Article

\title{
One-Electron Reduction Potentials: Calibration of Theoretical Protocols for Morita-Baylis-Hillman Nitroaromatic Compounds in Aprotic Media
}

\author{
Amauri Francisco da Silva, Antonio João da Silva Filho, Mário L. A. A. Vasconcellos and \\ Otávio Luís de Santana * \\ Chemistry Department, Federal University of Paraiba, João Pessoa 58051-900, Brazil; \\ amauriquimica@gmail.com (A.F.d.S.); antonio.sjf@gmail.com (A.J.d.S.F.); mlaav@quimica.ufpb.br (M.L.A.A.V.) \\ * Correspondence: otavio@quimica.ufpb.br; Tel.: +55-(83)-3216-7200
}

Received: 30 July 2018; Accepted: 11 August 2018; Published: 24 August 2018

\begin{abstract}
Nitroaromatic compounds-adducts of Morita-Baylis-Hillman (MBHA) reaction-have been applied in the treatment of malaria, leishmaniasis, and Chagas disease. The biological activity of these compounds is directly related to chemical reactivity in the environment, chemical structure of the compound, and reduction of the nitro group. Because of the last aspect, electrochemical methods are used to simulate the pharmacological activity of nitroaromatic compounds. In particular, previous studies have shown a correlation between the one-electron reduction potentials in aprotic medium (estimated by cyclic voltammetry) and antileishmanial activities (measured by the $\mathrm{IC}_{50}$ ) for a series of twelve MBHA. In the present work, two different computational protocols were calibrated to simulate the reduction potentials for this series of molecules with the aim of supporting the molecular modeling of new pharmacological compounds from the prediction of their reduction potentials. The results showed that it was possible to predict the experimental reduction potential for the calibration set with mean absolute errors of less than $25 \mathrm{mV}$ (about $0.6 \mathrm{kcal} \cdot \mathrm{mol}^{-1}$ ).
\end{abstract}

Keywords: Morita-Baylis-Hilman Adducts; biological activity; reduction potentials; medicinal chemistry

\section{Introduction}

Nitro compounds have been used against various diseases for over five decades [1-5] due to their wide range of pharmacological activity against bacteria [6,7], fungus [8], and tumors $[9,10]$ as well as malaria, leishmaniasis, and Chagas disease [11-14]. The pharmacological mechanism of these compounds generally involves enzymatic bioreduction facilitated by the electron acceptor strength of the nitro group, leading to formation of free radicals with preferential toxicity for invading microorganisms [15-19]. This mechanism of oxidative stress, which is responsible for damage to biological membranes, proteins, and DNA molecules [20,21], is the main route of pharmacologic action of this class of compounds [22,23]. An indicative of this mechanism is the experimental observation of the relationship between the reduction potential and the pharmacological action of some nitro compounds (greater biological activity correlated with the least negative potential), which can be used for modeling new bioactive compounds [24]. For this reason, electrochemical methods are considered useful tools for simulation of metabolic processes in vivo [25,26].

Biological antileishmaniasis activities (measured by the $\mathrm{IC}_{50}$ ) for a series of 12 nitroaromatic compounds (Figure 1) —adducts of Morita-Baylis-Hillman (MBHA) reaction—have been previously reported by researchers [25-27]. For this series, electrochemical studies were performed in aprotic media ( $N, N$-dimethylformamide plus tetrabutylammonium perchlorate $0.1 \mathrm{~mol} \cdot \mathrm{L}^{-1}$ for supporting electrolyte) using cyclic voltammetry with a conventional three-electrode cell and $\mathrm{Ag} \mid \mathrm{AgCl}, \mathrm{Cl}^{-}$ 
$\left(0.1 \mathrm{~mol} \cdot \mathrm{L}^{-1}\right)$ as reference electrode at $25^{\circ} \mathrm{C}\left( \pm 2{ }^{\circ} \mathrm{C}\right)$. In these conditions, three to four reduction waves were observed. The first cathodic peak $\left(E_{\mathrm{cp} 1}\right.$, values in parentheses in Figure 1$)$ was related to the generation of stable nitro-anion radicals in a diffusion-controlled reversible system. A strong relationship between antileishmaniasis $\mathrm{IC}_{50}$ and cathodic peak $E_{\mathrm{cp} 1}$ values was observed when comparing the inter-series of MBHA compounds $[25,26]$.<smiles>[R]C(=C)C(O)c1ccccc1[N+](=O)[O-]</smiles>

$\begin{array}{ll}\text { 1a: } \mathrm{R}=\mathrm{CN} & (-0.944 \mathrm{~V}) \\ \text { 2a: } \mathrm{R}=\mathrm{CO}_{2} \mathrm{CH}_{3} & (-1.061 \mathrm{~V}) \\ \text { 3a: } \mathrm{R}=\mathrm{CO}_{2} \mathrm{CH}_{2} \mathrm{CH}_{2} \mathrm{OH} & (-1.014 \mathrm{~V}) \\ \text { 4a: } \mathrm{R}=\mathrm{CO}_{2} \mathrm{CH}_{2} \mathrm{CH}_{2} \mathrm{CH}_{3} & (-1.009 \mathrm{~V})\end{array}$<smiles>[R]C(=C)C(O)c1cccc([N+](=O)[O-])c1</smiles>

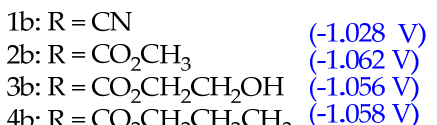<smiles>[R]C(=C)C(O)c1ccc([N+](=O)[O-])cc1</smiles>

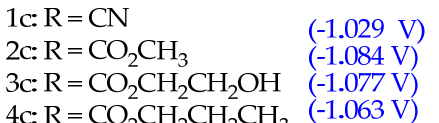

Figure 1. Chemical structures of the studied nitroaromatic Morita-Baylis-Hillman adducts (MBHA) and corresponding $E_{\mathrm{cp} 1}$ values.

This work aims to establish protocols with low computational cost for routine prediction of one-electron reduction potentials $E_{\text {ref }}^{0}$ (which is related to $E_{\mathrm{cp} 1}$ values) in aprotic media to assist the molecular modeling of new compounds with desired pharmacological activity.

\section{Theoretical Fundamentals}

\subsection{Determination of Reduction Potentials from Cyclic Voltammetry}

Diverse electrochemical techniques can be used for determining the standard reduction potentials

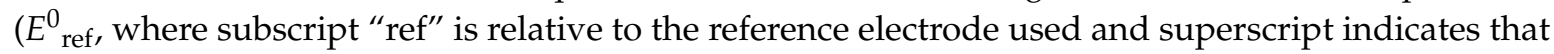
the species are in their standard states-concentration of $1 \mathrm{~mol} \cdot \mathrm{L}^{-1}$ in the condensed phase and temperature of $298 \mathrm{~K}$ ) [28-30]. Voltammetric techniques are often employed in the case of reversible redox reactions. In a reversible cyclic voltammogram, the cathodic $\left(E_{\mathrm{cp}}\right)$ and anodic $\left(E_{\mathrm{ap}}\right)$ peaks relate to the standard reduction potential by the following equation:

$$
E_{\text {ref }}^{0} \approx 1 / 2\left(E_{\mathrm{cp}}+E_{\mathrm{ap}}\right)
$$

For a redox reaction involving one electron (in standard conditions), the equation is as follows:

$$
\left|E_{\mathrm{cp}}-E_{\mathrm{ap}}\right| \approx 0.059 \mathrm{~V}
$$

In this case, it is possible to relate $E_{\text {ref }}^{0}$ with $E_{\mathrm{cp}}$ or $E_{\mathrm{ap}}$ :

$$
E_{\text {ref }}^{0} \approx E_{\mathrm{cp}}+0.030 \mathrm{~V}
$$

For reversible processes, the error of this method is usually as low as $0.01-0.02 \mathrm{~V}$ [29].

\subsection{Theoretical Determination of Reduction Potentials}

The computational procedures employed for predicting reduction potentials can be classified in two types [30-39]: (i) "direct", when the reduction potential of the half-reaction for a molecular entity $\mathrm{M}$ is calculated directly between their solvated oxidized $\left(\mathrm{M}_{(\mathrm{svt})}\right)$ and reduced $\left(\mathrm{M}^{-}{ }_{(\mathrm{svt})}\right)$ forms and (ii) "indirect", when the calculation is based on a thermodynamic cycle (Scheme 1) [40]. The direct procedure is computationally simpler but although formally correct [41], it generally leads to unsatisfactory results. For this reason, the indirect procedure is commonly employed combining different methods of electronic structure at various steps of thermodynamic cycle [42-47]. This aspect, while usually enabling a higher accuracy, also confers more complexity to the theoretical treatment 
and generally requires the use of computational methods of high demand for species in gas phase, making it impractical as a routine method in some cases.

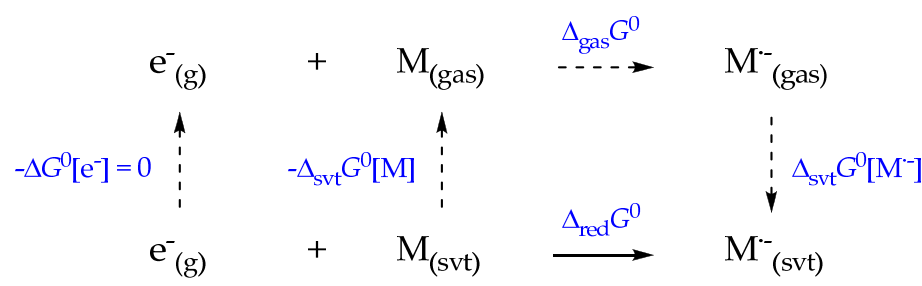

Scheme 1. Thermodynamic cycle used to describe the composition of $\Delta_{\text {red }} G^{0}$ and corresponding reduction potential. The solid arrow indicates the direct calculation, and dashed arrows indicate the indirect calculation path.

The thermodynamic cycle describes the half-reaction of interest (horizontal solid arrow in Scheme 1) that occurs in solution as a result of two fundamentally different processes: reduction (horizontal dashed arrow) and solvation (vertical dashed arrows). This observation allows the deficiency of the direct procedure to be assigned to a lack of calibration of used method, especially as the basis set functions. For example, extensive basis with diffuse and polarization functions correctly describes the anionic structures in a reduction process [48-50], but the description of the solvation process can be affected when implicit models are used [51,52]. For this reason, a better application of the direct procedure can be obtained from a systematic study to determine the appropriate combination of methods (basis set, electronic structure, and solvation methods). Calibration procedures can also be an important step for indirect methodologies [53].

\subsubsection{Direct Method}

The prediction of experimental standard potential—expressed by Equation (3)—under direct procedure consists of the calculation of free energy $\Delta_{\text {red }} G^{0}$ of redox half-reaction (written by convention as a reduction reaction) for the solvated species (horizontal solid arrow in Scheme 1) [40]. A neutral compound $\mathrm{M}$ in a process of one electron can be expressed as follows:

$$
\mathrm{M}_{(\mathrm{svt})}+\mathrm{e}^{-}{ }_{(\mathrm{g})} \rightarrow \mathrm{M}^{-}(\mathrm{svt})
$$

The absolute standard reduction potential $E_{\text {abs }}^{0}$ is calculated from the free energy of the reaction according to the thermodynamic relation:

$$
E_{\text {abs }}^{0}=-\Delta_{\text {red }} G^{0} / F
$$

where $F$ is the Faraday constant.

Experimental reduction potentials are obtained with respect to a reference, such as the normal hydrogen electrode (NHE):

$$
\mathrm{H}+{ }_{(\mathrm{aq})}+\mathrm{e}^{-}{ }_{(\mathrm{g})} \rightarrow \frac{1}{2} \mathrm{H}_{2(\mathrm{~g})}
$$

with absolute reduction potential $E^{0}{ }_{\mathrm{NHE}}$ defined according to Equation (5). Experimental and theoretical estimates for this quantity still have large uncertainties (ranging from $+4.80 \mathrm{~V}$ to $+4.28 \mathrm{~V})$ [28,54-59]. The most recent estimate, which is used in this study, corresponds to $E^{0}{ }_{\mathrm{NHE}} \approx+4.280 \mathrm{~V}$ (under standard conditions). In relation to this reference electrode, the reduction potential of the species $\mathrm{M}$ can be expressed as follows:

$$
E_{\text {ref( }(\mathrm{NHE})}^{0}=E_{\text {abs }}^{0}-E^{0}{ }_{\mathrm{NHE}} \approx-\Delta_{\mathrm{red}} G^{0} / F-4.280 \mathrm{~V}
$$


Reduction potentials of other reference electrodes are tabulated relative to the NHE. For the silver/silver chloride electrode (SSC, $\mathrm{Ag} \mid \mathrm{AgCl}_{1} \mathrm{Cl}^{-} 0.1 \mathrm{~mol} \cdot \mathrm{L}^{-1}$ ) [60]:

$$
\left.\mathrm{AgCl}_{(\mathrm{s})}+\mathrm{e}^{-}(\mathrm{g}) \rightarrow \mathrm{Ag}_{(\mathrm{s}}\right)+\mathrm{Cl}^{-}(\mathrm{aq})
$$

for which,

$$
E_{\mathrm{SSC}(\mathrm{NHE})}^{0}=E_{\mathrm{SSC}}^{0}-E_{\mathrm{NHE}}^{0} \approx+0.222 \mathrm{~V}
$$

so that

$$
E_{\text {ref(SSC) }}^{0}=E_{\text {abs }}^{0}-E_{\text {SSC }}^{0} \approx-\Delta_{\text {red }} G^{0} / F-4.502 \mathrm{~V}
$$

According to Equation (10), only the free energy of the half-reaction of Equation (4) in the direct procedure is needed to be determined computationally.

\subsubsection{Indirect Method}

In the indirect procedure, the free energy of the half-reaction in solution $\left(\Delta_{\text {red }} G^{0}\right)$ —expressed by Equation (4) - is partitioned in three contributions: free energy of the reduction half-reaction in gas phase $\left(\Delta_{\text {gas }} G^{0}\right)$ and the solvation free energy of compound $\mathrm{M}$ in the neutral $\left(\Delta_{\text {svt }} G^{0}[\mathrm{M}]\right)$ and reduced $\left(\Delta_{\mathrm{svt}} G^{0}\left[\mathrm{M}^{-}\right]\right)$states:

$$
\Delta_{\text {red }} G^{0}=\Delta_{\text {gas }} G^{0}+\Delta_{\text {svt }} G^{0}\left[\mathrm{M}^{-}\right]-\Delta_{\text {svt }} G^{0}[\mathrm{M}]=\Delta_{\text {gas }} G^{0}+\Delta \Delta_{\text {svt }} G^{0}
$$

so that $E_{\text {ref(SSC) }}^{0}$ can be calculated from Equation (11) into Equation (10). This procedure is useful when different electronic structure methods are used to calculate the gas phase (with accurate level of theory) and solvation contributions (with electronic structure method and basis sets consistent with those used in the calibration of the solvation model) [42-47]. In the general case, the solvation contribution-considered the major source of inaccuracies in redox potentials predictions-should take into account the compression work necessary to bring the system from the standard state in the gas phase (under $1 \mathrm{~atm}$ ) to the standard state in the condensed phase (under $1 \mathrm{~mol} \cdot \mathrm{L}^{-1}$ ) [56]. However, when the number of fragments of reactants and products that move from the gas phase to solution are the same-as in the present case- the compression terms cancels out.

\section{Computational Details}

All quantum chemistry calculations for a series of 12 MBHA with direct protocol were performed using the Gaussian 09 [61] software. Global minima for neutral species were determined at $\mathrm{HF} / 6-31+\mathrm{G}(\mathrm{d})$ level [25]. All structures in their neutral and reduced states were reoptimized with default convergence criteria at HF [62] level, and the effect of basis set size were tested with double and triple-zeta Pople's basis adding progressively diffuse and polarization functions [63]. The solvent effect was taken into account using the C-PCM [64] and SMD [65] continuum solvation models for $\mathrm{N}, \mathrm{N}$-dimethylformamide (DMF), with cavitation generated by atomic radii of UFF topological model and van der Waals surface. Frequency calculations were carried out for neutral and reduced species and used to characterize the optimized structures as stationary minima. Free energies of neutral and reduced states were obtained at $1 \mathrm{~atm}$ and $25^{\circ} \mathrm{C}$ from the ideal gas partition functions for the structures optimized in solution [41]. The standard reduction potentials were predicted from free energies of half-reaction according to Equation (10), and the quality of the protocol was assessed by comparison

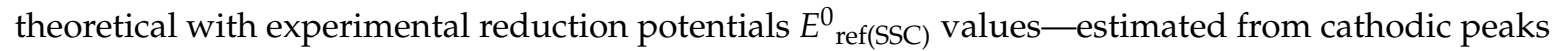
$E_{\mathrm{cp} 1}$ and Equation (3) - considering the mean absolute errors $\left(e_{\mathrm{abs}}\right)$ and standard deviation of absolute errors $\left(\sigma_{\text {abs }}\right)$. The basis sets and solvation model, which provide the smallest mean absolute errors, were selected for DFT calculations, with BP86 [66], B98 [42], B3LYP [53], PBE1PBE [67], and M06-2X [68] functionals. Dispersion effects were taken into account from Grimme's empirical corrections of type 3 (D3, from Gaussian overlay 3/124) [69,70]. 
The gas phase contributions for indirect protocol was calculated with functionals selected from direct protocol calibration. All structures in their neutral and reduced states were reoptimized with default convergence criteria with $6-311+G(d, p)$ basis, and frequency calculations were carried out in order to characterize the structures as stationary minima. Corrections in the electronic energy were obtained from single point calculations with $6-311++G(3 \mathrm{df}, 2 \mathrm{pd})$ basis set. The solvation contributions was determined from HF and DFT calculations (with the same functional used for gas phase contribution) with two basis sets: 6-31G(p) (the same employed in the continuum solvation model calibration) $[5,6]$ and $6-31+G(p)$ (to take into account the anionic products). The solvent effect was taken into account using the continuum solvation model selected from direct protocol calibration, with the same cavitation parameters. All structures in their neutral and reduced states were reoptimized with default convergence criteria for each method used, followed by frequency calculations to characterize the structures as stationary minima. Free energies of neutral and reduced states were obtained at $1 \mathrm{~atm}$ and $25^{\circ} \mathrm{C}$ from the ideal gas partition functions, and the standard reduction potentials were predicted from free energies of half-reaction according to Equations (10) and (11). The quality of the protocol was assessed by comparison theoretical with experimental reduction potentials values considering the mean absolute errors $\left(e_{\mathrm{abs}}\right)$ and standard deviation of absolute errors $\left(\sigma_{\mathrm{abs}}\right)$.

\section{Results}

The mean absolute errors and standard deviation of absolute errors-obtained at HF level with C-PCM and SMD solvation models-are summarized in Table 1 (the complete data set are shown in Supporting Information). With C-PCM solvation model, starting from 6-31G (BS1) basis set, a mean absolute error of about $430 \mathrm{mV}$ was obtained (this error was greater than window of experimental values of $140 \mathrm{mV}$ ). The inclusion of a set of diffuse functions on heavy atoms (BS2) led to an increase in absolute errors by $450 \mathrm{mV}$, while the inclusion of a set of polarization functions on heavy atoms (BS3) led to an increase of approximately $70 \mathrm{mV}$. However, the combined use of polarization and diffuse functions-corresponding to 6-31+G(d) (BS4) basis set-led to a reduction in error by approximately $400 \mathrm{mV}$. The remaining mean absolute error $\left(38 \mathrm{mV}, \sim 0.88 \mathrm{kcal} \cdot \mathrm{mol}^{-1}\right)$ was much lower than the uncertainty in the absolute potential of hydrogen reference electrode, and the standard deviation of absolute errors $\left(23 \mathrm{mV}, \sim 0.53 \mathrm{kcal} \cdot \mathrm{mol}^{-1}\right)$ was comparable to experimental uncertainty of voltammetric techniques for reduction potentials determination. The basis sets 6-31+G(d,p) (BS6) and 6-31++G(d,p) (BS7) with C-PCM solvation model led to similar results. All results with SMD solvation model and direct protocol were greater than $50 \mathrm{mV}$.

Table 1. Mean absolute errors $\left(e_{\mathrm{abs}}\right)$ and standard deviation of absolute errors $\left(\sigma_{\mathrm{abs}}\right)$ for theoretical values of 12 investigated nitroaromatic Morita-Baylis-Hillman adducts (MBHA) calculated at Hartree-Fock (HF) level with C-PCM and SMD continuum solvation models from direct protocol. Values in millivolts.

\begin{tabular}{|c|c|c|c|c|c|c|c|c|c|}
\hline & BS1 $^{a}$ & BS2 & BS3 & BS4 & BS5 & BS6 & BS7 & BS8 & BS9 \\
\hline \multicolumn{10}{|c|}{ HF/C-PCM } \\
\hline$e_{\mathrm{abs}}$ & 433 & 887 & 506 & 38 & 199 & 41 & 39 & 66 & 204 \\
\hline$\sigma_{\mathrm{abs}}$ & 79 & 36 & 62 & 23 & 36 & 22 & 24 & 29 & 38 \\
\hline \multicolumn{10}{|c|}{ HF/SMD } \\
\hline$e_{\mathrm{abs}}$ & 65 & 478 & 869 & 410 & 186 & 408 & 400 & 431 & 581 \\
\hline$\sigma_{\mathrm{abs}}$ & 78 & 57 & 93 & 54 & 57 & 63 & 51 & 57 & 55 \\
\hline
\end{tabular}

The window of experimental reduction potentials investigated was quite narrow $(\sim 140 \mathrm{mV})$. In this region, an important qualitative result to be analyzed was the ordering of the theoretical potentials. Despite the fact that in some cases the differences in the reduction potentials values between 
different types of nitroaromatics (1-4) and isomers $(a-c)$ were less than $20 \mathrm{mV}\left(\sim 0.5 \mathrm{kcal} \cdot \mathrm{mol}^{-1}\right)$, the experimental potentials followed the ordering: $1>4>3>2$ (between groups) and $a>b>c$ (between isomers). Although the results obtained with $6-31+\mathrm{G}(\mathrm{d})$ basis set led to a relatively small mean absolute error, it provided one incorrect ordering inside the groups $(1 c>1 b$, as shown in Table 2). The inclusion of a set of diffuse functions to light atoms increased the mean absolute error, while the inclusion of polarization functions left the error almost unchanged but with the correct ordering of potentials between isomers in all cases. The combined effect of these two additional sets kept the average error near the values obtained with $6-31+G(d)$ basis set but with one incorrect ordering $(2 b>2 a)$. The others tested expansions in basis sets progressively increased the average absolute errors for values greater than $50 \mathrm{mV}$.

Table 2. Theoretical reduction potentials calculated at HF level with C-PCM continuum solvation model of 12 investigated nitroaromatic MBHA. Reduction potentials values are in volts. Mean absolute errors $\left(e_{\mathrm{abs}}\right)$, standard deviation of absolute errors $\left(\sigma_{\mathrm{abs}}\right)$, and range of experimental values $\left(E^{0}{ }_{\max }-E^{0}{ }_{\min }\right)$ are in millivolts.

\begin{tabular}{|c|c|c|c|c|c|}
\hline \multirow{2}{*}{ Est. } & \multicolumn{3}{|c|}{ Theoretical: HF/C-PCM [V] } & \multicolumn{2}{|c|}{ Experimental [V] } \\
\hline & $\mathrm{sBF1}^{\mathrm{a}}$ & sBF2 & sBF3 & $E_{\mathrm{cp} 1}$ & $E_{\text {ref(SSC) }}^{0}$ \\
\hline $1 a$ & -0.929 & -0.933 & -0.900 & -0.944 & -0.915 \\
\hline $1 b$ & -1.000 & -1.013 & -1.012 & -1.028 & -0.999 \\
\hline $1 c$ & -0.993 & -1.015 & -1.014 & -1.029 & -1.000 \\
\hline $2 a$ & -1.064 & -1.056 & -1.055 & -1.061 & -1.032 \\
\hline $2 b$ & -1.080 & -1.067 & -1.050 & -1.062 & -1.033 \\
\hline $2 c$ & -1.090 & -1.084 & -1.082 & -1.084 & -1.055 \\
\hline $3 a$ & -0.939 & -0.925 & -0.926 & -1.014 & -0.985 \\
\hline $3 b$ & -1.066 & -1.074 & -1.074 & -1.056 & -1.027 \\
\hline $3 c$ & -1.096 & -1.100 & -1.104 & -1.077 & -1.048 \\
\hline $4 a$ & -1.066 & -1.066 & -1.067 & -1.009 & -0.980 \\
\hline $4 b$ & -1.069 & -1.078 & -1.074 & -1.058 & -1.029 \\
\hline $4 c$ & -1.092 & -1.096 & -1.097 & -1.063 & -1.034 \\
\hline$e_{\mathrm{abs}}$ & 38 & 41 & 39 & \multirow{2}{*}{$E^{0}{ }_{\max }-E^{0}{ }_{\min }$} & \multirow[b]{2}{*}{140} \\
\hline$\sigma_{\mathrm{abs}}$ & 23 & 22 & 24 & & \\
\hline
\end{tabular}

The three basis sets that led mean absolute errors less than $50 \mathrm{mV}$ were selected to perform DFT calculations. The results are summarized in Table 3 (the complete set of data are shown in Supporting Information). In general, the inclusion of empirical dispersion correction marginally reduced the mean absolute error, with the exception of B3LYP and M06-2X functionals. The B98+D3, mPW1PW91+D3 and M06-2X functionals provided better statistical results with all basis sets (with $e_{\mathrm{abs}}<25 \mathrm{mV}$ and $\sigma_{\text {abs }}<20 \mathrm{mV}$ or $\sim 0.6 \mathrm{kcal} \cdot \mathrm{mol}^{-1}$ and $\sim 0.5 \mathrm{kcal} \cdot \mathrm{mol}^{-1}$, respectively). The results from B98+D3 functional provided one incorrect ordering inside the groups $(1 b<1 c)$ and from mPW1PW91+D3 functional two incorrect ordering $(1 b<1 c$ and $2 b<2 c)$ with all basis set. Functional M06-2X functional provided an incorrect ordering only with $6-31+G(d)$ basis set. For this reason, two direct protocols were selected with the aim of achieving the lowest computational cost with highest predictive power: B98+D3/6-31+G(d) and M06-2X/6-31+G(d,p).

The two functionals that led to the lowest mean absolute errors were selected for calibration of indirect protocol. The results are summarized in Table 4 (the complete set of data are shown in Supporting Information). All results obtained with solvation contribution estimated from HF calculations presented errors greater than those obtained with the corresponding functionals. In addition, the results obtained with the basis set $6-31+G(d)$ resulted in the smallest mean absolute errors. This result was expected due to the presence of anionic products, which require the inclusion of diffuse functions for better description. However, the B98+D3 functional provided less satisfactory 
results with indirect protocol than those obtained with direct calculations (with $e_{\mathrm{abs}}>50 \mathrm{mV}$ and $\left.\sigma_{\mathrm{abs}}>30 \mathrm{mV}\right)$.

Table 3. Mean absolute errors $\left(e_{\mathrm{abs}}\right)$ and standard deviation of absolute errors $\left(\sigma_{\mathrm{abs}}\right)$ for theoretical values of 12 investigated nitroaromatic MBHA calculated at DFT level with C-PCM continuum solvation model from direct protocol. Values are in millivolts.

\begin{tabular}{|c|c|c|c|c|c|c|c|c|c|c|}
\hline & DF1 ${ }^{a}$ & $\mathrm{DF}^{+}$ & DF2 & $\mathrm{DF}^{+}$ & DF3 & $\mathrm{DF}^{+}$ & DF4 & $\mathrm{DF}^{+}{ }^{+}$ & DF5 & DF5 $^{+}$ \\
\hline & \multicolumn{10}{|c|}{ 6-31+G(d)/C-PCM } \\
\hline$e_{\mathrm{abs}}$ & 55 & 61 & 23 & 20 & 31 & 27 & 31 & 24 & 24 & 27 \\
\hline \multirow[t]{2}{*}{$\sigma_{\mathrm{abs}}$} & 26 & 24 & 20 & 16 & 22 & 21 & 23 & 16 & 14 & 17 \\
\hline & \multicolumn{10}{|c|}{ 6-31+G(d,p)/C-PCM } \\
\hline$e_{\mathrm{abs}}$ & 57 & 65 & 23 & 21 & 30 & 27 & 26 & 24 & 23 & 27 \\
\hline \multirow[t]{2}{*}{$\sigma_{\text {abs }}$} & 24 & 24 & 18 & 13 & 21 & 19 & 17 & 14 & 14 & 19 \\
\hline & \multicolumn{10}{|c|}{ 6-31++G(d,p)/C-PCM } \\
\hline$e_{\mathrm{abs}}$ & 59 & 63 & 22 & 23 & 28 & 26 & 26 & 25 & 24 & 28 \\
\hline$\sigma_{\mathrm{abs}}$ & 24 & 25 & 17 & 15 & 21 & 18 & 18 & 14 & 14 & 22 \\
\hline
\end{tabular}

${ }^{\mathrm{a}} \mathrm{DF}=$ Density Functional: DF1 = B3LYP; $\mathrm{DF}^{+}=\mathrm{B} 3 \mathrm{LYP}+\mathrm{D} 3 ; \mathrm{DF} 2=\mathrm{B} 98 ; \mathrm{DF}^{+}=$B98+D3; DF3 = PBE1PBE; $\mathrm{DF}^{+}=$PBE1PBE+D3; DF4 = mPW1PW91; DF4 ${ }^{+}=$mPW1PW91+D3; DF5 = M06-2X; DF5 ${ }^{+}=$M06-2X+D3.

Table 4. Mean absolute errors $\left(e_{\mathrm{abs}}\right)$ and standard deviation of absolute errors $\left(\sigma_{\mathrm{abs}}\right)$ for theoretical values of 12 investigated nitroaromatic MBHA calculated at DFT level with C-PCM continuum solvation model from indirect protocol. Values are in millivolts.

\begin{tabular}{lcccc}
\hline Gas & \multicolumn{4}{c}{ B98+D3/6-311++G(3df,2pd)//B98+D3/6-311+G(d,p) } \\
\hline SVT & HF/BF1 ${ }^{\text {a }}$ & HF/BF2 & B98+D3/BF1 & B98+D3/BF2 \\
\hline $\boldsymbol{e}_{\text {abs }}$ & 293 & 303 & 143 & 75 \\
$\sigma_{\text {abs }}$ & 106 & 116 & 55 & 34 \\
\hline Gas & M06-2X/6-311++G(3df,2pd)//M06-2X/6-311+G(d,p) \\
\hline SVT & HF/BF1 & HF/BF2 & M06-2X/BF1 & M06-2X/BF2 \\
\hline $\boldsymbol{e}_{\text {abs }}$ & 248 & 221 & 69 & 16 \\
$\sigma_{\text {abs }}$ & 153 & 84 & 40 & 16 \\
\hline \multicolumn{5}{c}{${ }^{a}$ BF = Base Functions: BF1 = 6-31G(d); BF2 =6-31+G(d). }
\end{tabular}

The predicted reduction potentials at DFT level from direct and indirect calibrated protocols for investigated nitroaromatic MBHA are shown in Table 5. With B98 functional, the results obtained by direct procedure had thermochemical precision $\left(e_{\mathrm{abs}}<43 \mathrm{mV}\right.$ or $\left.1 \mathrm{kcal} \cdot \mathrm{mol}^{-1}\right)$, which did not occur with the indirect protocol. On the other hand, although the predictions obtained with the M06-2X functional had the necessary precision with both protocols, it is important to consider the greater simplicity of the direct calculation, which is consequently reflected in the considerably lower computational cost. This result is consistent with that observed in other investigations [71-73]. In addition, only the direct protocol with the M06-2X functional predicted the correct ordering throughout the series. 
Table 5. Theoretical reduction potentials calculated at DFT level with C-PCM continuum solvation model of 12 investigated nitroaromatic MBHA. Reduction potentials values are in volts, mean absolute errors $\left(e_{\mathrm{abs}}\right)$ and standard deviation of absolute errors $\left(\sigma_{\mathrm{abs}}\right)$ are in millivolts.

\begin{tabular}{|c|c|c|c|c|c|}
\hline Est. & B98/Direct ${ }^{a}$ & B98/Indirect ${ }^{b}$ & M06-2X/Direct ${ }^{c}$ & M06-2X/Indirect ${ }^{\mathrm{d}}$ & Exp. \\
\hline $1 a$ & -0.931 & -0.990 & -0.922 & -0.974 & -0.915 \\
\hline $1 b$ & -0.982 & -1.041 & -0.960 & -0.982 & -0.999 \\
\hline $1 c$ & -0.965 & -1.006 & -1.008 & -1.003 & -1.000 \\
\hline $2 a$ & -1.014 & -1.087 & -0.991 & -1.026 & -1.032 \\
\hline $2 b$ & -1.030 & -1.091 & -1.010 & -1.059 & -1.033 \\
\hline $2 c$ & -1.065 & -1.170 & -1.041 & -1.054 & -1.055 \\
\hline $3 a$ & -0.984 & -1.051 & -0.969 & -0.988 & -0.985 \\
\hline $3 b$ & -1.035 & -1.098 & -0.976 & -1.006 & -1.027 \\
\hline $3 c$ & -1.075 & -1.144 & -1.025 & -1.072 & -1.048 \\
\hline $4 a$ & -1.025 & -1.086 & -0.950 & -0.995 & -0.980 \\
\hline $4 b$ & -1.041 & -1.104 & -1.011 & -1.041 & -1.029 \\
\hline $4 c$ & -1.081 & -1.166 & -1.021 & -1.044 & -1.034 \\
\hline$e_{\mathrm{abs}}$ & 20 & 75 & 23 & 16 & - \\
\hline$\sigma_{\mathrm{abs}}$ & 16 & 34 & 14 & 16 & - \\
\hline
\end{tabular}

\section{Conclusions}

In this work, the calibration of two computational protocols to predict the one-electron reduction potentials in an aprotic medium was performed from a calibration set consisting of 12 molecules that exhibit antileishmaniasis activity. The first calibrated computational protocol was based on a direct calculation procedure in which the free energies of the oxidized and reduced forms of the molecule under study were computed directly in the solvated phase. The second protocol-the most commonly used in this research area-was based on a thermodynamic cycle that makes it possible to separate the free energy of the reduction reaction in contributions from gas and solvated phases, which are computed separately at different calculation levels, assuming that an errors cancellation can produce better results. In both cases, the calibration was based on the selection of the electronic structure method, basis set, and continuous solvation model that minimizes the mean absolute error and standard deviation. The calibration set was composed of 12 compounds of interest for which the reduction potentials were experimentally determined by cyclic voltammetry covering a window of potentials of only $140 \mathrm{mV}$ (approximately $3 \mathrm{kcal} \cdot \mathrm{mol}^{-1}$ of difference between data set extremes). The results showed that the experimental reduction potential can be predicted with thermochemical accuracy $\left(<43 \mathrm{mV}, \sim 1 \mathrm{kcal} \cdot \mathrm{mol}^{-1}\right)$, with mean absolute errors lower than $25 \mathrm{mV}$ (lower than uncertainty in the absolute potential of reference hydrogen electrode, without inclusion of corrective terms) and standard deviation of the order of $15 \mathrm{mV}$ (comparable to experimental uncertainty).

Although several parameters are related to the biological activity of a given class of compounds, there are theoretical and experimental reasons to assume that the reduction potential is an important parameter in the pharmacological mechanism of nitroaromatic compounds. Therefore, the development of a theoretical protocol for the prediction of reduction potentials may be useful in the modeling of new nitroaromatic compounds with the desired biological activity. However, in order for the calibrated protocols to be routinely used for molecular modeling of new drug candidates from the prediction of their reduction potentials, it is necessary to verify if they are transferable to other molecular systems. This study is currently underway in our research group.

Supplementary Materials: The following are available online.

Author Contributions: Conceptualization: M.L.A.A.V. and O.L.d.S.; Investigation and Data Curation: A.F.d.S. and A.J.d.S.F.; Methodology, Formal Analysis and Writing-Original Draft: O.L.d.S.

Funding: This research received no external funding. 
Acknowledgments: The authors are grateful to National Council for Scientific and Technological Development $(\mathrm{CNPq})$, Coordination for the Improvement of Higher Education Personnel (CAPES), National Center for High Performance Processing in São Paulo (CENAPAD/Unicamp) and Ceara (CENAPAD/UFC) and the Graduate Program in Chemistry (PPGQ/UFPB).

Conflicts of Interest: The authors declare no conflict of interest.

\section{References}

1. Dodd, M.C.; Stillman, W.B. The in vitro bacteriostatic action of some simple furan derivatives. J. Pharmacol. Exp. Ther. 1944, 82, 11-18.

2. Hofmann, K.; Chen, C.; Bridgwater, A.; Axelrod, A.E. Furan and Tetrahydrofuran Derivatives. VII. The Synthesis and Biological Activity of a Number of Oxybiotin Homologs1. J. Am. Chem. Soc. 1947, 69, 191-195. [CrossRef] [PubMed]

3. Ward, W.C.; Dodd, M.C. A Comparative Study of the in Vitro Bacteriostatic Action of Some Simple Derivatives of Furan, Thiophene, and Pyrrole. J. Bacteriol. 1948, 56, 649-652. [PubMed]

4. Raether, W.; Hänel, H. Nitroheterocyclic drugs with broad spectrum activity. Parasitol. Res. 2003, 90 (Suppl. 1), S19-S39. [CrossRef]

5. Horrocks, S.M.; Jung, Y.S.; Huwe, J.K.; Harvey, R.B.; Ricke, S.C.; Carstens, G.E.; Callaway, T.R.; Anderson, R.C.; Ramlachan, N.; Nisbet, D.J. Effects of short-chain nitrocompounds against Campylobacter jejuni and Campylobacter coli in vitro. J. Food Sci. 2007, 72, M50-M55. [CrossRef] [PubMed]

6. Rajan, Y.C.; Kanakam, C.C.; Selvam, S.P.; Murugesan, K. A study on the synthesis and biological and optical properties of methylene-dinaphthyl bis-chromanones: The utility of Baylis-Hillman adducts. Tetrahedron Lett. 2007, 48, 8562-8565. [CrossRef]

7. Al-Zereini, W.; Schuhmann, I.; Laatsch, H.; Helmke, E.; Anke, H. New Aromatic Nitro Compounds from Salegentibacter sp. T436, an Arctic Sea Ice Bacterium: Taxonomy, Fermentation, Isolation and Biological Activities. J. Antibiot. 2007, 60, 301-308. [CrossRef] [PubMed]

8. Narender, P.; Srinivas, U.; Ravinder, M.; Rao, B.A.; Ramesh, C.; Harakishore, K.; Gangadasu, B.; Murthy, U.S.N.; Rao, V.J. Synthesis of multisubstituted quinolines from Baylis-Hillman adducts obtained from substituted 2-chloronicotinaldehydes and their antimicrobial activity. Bioorg. Med. Chem. 2006, 14, 4600-4609. [CrossRef] [PubMed]

9. Kohn, L.K.; Pavam, C.H.; Veronese, D.; Coelho, F.; de Carvalho, J.E.; Almeida, W.P. Antiproliferative effect of Baylis-Hillman adducts and a new phthalide derivative on human tumor cell lines. Eur. J. Med. Chem. 2006, 41, 738-744. [CrossRef] [PubMed]

10. Mohan, R.; Rastogi, N.; Namboothiri, I.N.N.; Mobin, S.M.; Panda, D. Synthesis and evaluation of alpha-hydroxymethylated conjugated nitroalkenes for their anticancer activity: Inhibition of cell proliferation by targeting microtubules. Bioorg. Med. Chem. 2006, 14, 8073-8085. [CrossRef] [PubMed]

11. Narender, P.; Srinivas, U.; Gangadasu, B.; Biswas, S.; Rao, V.J. Anti-malarial activity of Baylis-Hillman adducts from substituted 2-chloronicotinaldehydes. Bioorg. Med. Chem. Lett. 2005, 15, 5378-5381. [CrossRef] [PubMed]

12. De Souza, R.O.M.A.; Pereira, V.L.P.; Muzitano, M.F.; Falcão, C.A.B.; Rossi-Bergmann, B.A.; Filho, E.B.; Vasconcellos, M.L.A.A. High selective leishmanicidal activity of 3-hydroxy-2-methylene-3(4-bromophenyl)propanenitrile and analogous compounds. Eur. J. Med. Chem. 2007, 42, 99-102. [CrossRef] [PubMed]

13. Barbosa, T.P.; Lima-Júnior, C.G.; Silva, F.P.L.; Lopes, H.M.; Figueiredo, L.R.F.; Sousa, S.C.O.; Batista, G.N.; da Silva, T.G.; Silva, T.M.S.; de Oliveira, M.R.; et al. Improved synthesis of seven aromatic Baylis-Hillman adducts (BHA): Evaluation against Artemia salina Leach. and Leishmania chagasi. Eur. J. Med. Chem. 2009, 44, 1726-1730. [CrossRef] [PubMed]

14. Sandes, J.M.; Borges, A.R.; Lima-Júnior, C.G.; Silva, F.P.L.; Carvalho, G.A.U.; Rocha, G.B.; Vasconcellos, M.L.A.A.; Figueiredo, R.C.B.Q. 3-Hydroxy-2-methylene-3-(4-nitrophenylpropanenitrile): A new highly active compound against epimastigote and trypomastigote form of Trypanosoma cruzi. Bioorg. Chem. 2010, 38, 190-195. [CrossRef] [PubMed]

15. Kappus, H. Overview of enzyme systems involved in bio-reduction of drugs and in redox cycling. Biochem. Pharmacol. 1986, 35, 1-6. [CrossRef] 
16. Viodé, C.; Bettache, N.; Cenas, N.; Krauth-Siegel, R.L.; Chauvière, G.; Bakalara, N.; Périé, J. Enzymatic reduction studies of nitroheterocycles. Biochem. Pharmacol. 1999, 57, 549-557. [CrossRef]

17. Yan, X.-F.; Xiao, H.-M.; Gong, X.-D.; Ju, X.-H. Quantitative structure-activity relationships of nitroaromatics toxicity to the algae (Scenedesmus obliguus). Chemosphere 2005, 59, 467-471. [CrossRef] [PubMed]

18. Maya, J.D.; Cassels, B.K.; Iturriaga-Vásquez, P.; Ferreira, J.; Faúndez, M.; Galanti, N.; Ferreira, A.; Morello, A. Mode of action of natural and synthetic drugs against Trypanosoma cruzi and their interaction with the mammalian host. Comp. Biochem. Phys. Part A 2007, 146, 601-620. [CrossRef] [PubMed]

19. Paula, F.R.; Serrano, S.H.P.; Tavares, L.C. Aspectos Mecanísticos da Bioatividade e Toxicidade de Nitrocompostos. Quim. Nova 2009, 32, 1013-1020. [CrossRef]

20. Edwards, D.I. Reduction of nitroimidazoles in vitro and DNA damage. Biochem. Pharmacol. 1986, 35, 53-58. [CrossRef]

21. Tocher, J.H. Reductive activation of nitroheterocyclic compounds. Gen. Pharmacol. 1997, 28, 485-487. [CrossRef]

22. Maya, J.D.; Repetto, Y.; Agosín, M.; Ojeda, J.M.; Tellez, R.; Gaule, C.; Morello, A. Effects of nifurtimox and benznidazole upon glutathione and trypanothione content in epimastigote, trypomastigote and amastigote forms of Trypanosoma cruzi. Mol. Biochem. Parasitol. 1997, 86, 101-106. [CrossRef]

23. Maya, J.D.; Bollo, S.; Nuñez-Vergara, L.J.; Squella, J.A.; Repetto, Y.; Morello, A.; Périé, J.; Chauvière, G. Trypanosoma cruzi: Effect and mode of action of nitroimidazole and nitrofuran derivatives. Biochem. Pharmacol. 2003, 65, 999-1006. [CrossRef]

24. Rozenski, J.; De Ranter, C.J.; Verplanken, H. Quantitative Structure-Activity Relationships for Antimicrobial Nitroheterocyclic Drugs. Quant. Struct. Act. Relatsh. 1995, 14, 134-141. [CrossRef]

25. De Paiva, Y.G.; De Souza, A.A.; Lima-Júnior, C.G.; Silva, F.P.L.A.; Filho, E.B.; de Vasconcelos, C.C.; de Abreu, F.C.; Goulart, M.O.F.; Vasconcellos, M.L.A.A. Correlation between electrochemical and theoretical studies on the leishmanicidal activity of twelve Morita-Baylis-Hillman adducts. J. Braz. Chem. Soc. 2012, 23, 894-904. [CrossRef]

26. Lima-Júnior, C.G.; Vasconcellos, M.L.A.A. Morita-Baylis-Hillman adducts: Biological activities and potentialities to the discovery of new cheaper drugs. Bioorg. Med. Chem. 2012, 20, 3954-3971. [CrossRef] [PubMed]

27. Santos, M.S.; Coelho, F.; Lima-Junior, C.; Vasconcellos, M. The Morita-Baylis-Hillman Reaction: Advances and Contributions from Brazilian Chemistry. Curr. Org. Synth. 2015, 12, 830-852. [CrossRef]

28. Bard, A.J.; Faulkner, L.R. Electrochemical Methods: Fundamentals and Applications, 2nd ed.; John Wiley \& Sons, Inc.: Hoboken, NJ, USA, 2001; ISBN 0471043729.

29. Skoog, D.A.; West, D.M.; Holler, F.J.; Crouch, S.R. Fundamentals of Analytical Chemistry, 9th ed.; Cengage Learning: Boston, MA, USA, 2013; ISBN 9780495558286.

30. Junming, H.; Coote, M.L.; Cramer, C.J.; Truhlar, D.G. Theoretical Calculation of Reduction Potentials. In Organic Electrochemistry; CRC Press: Boca Raton, FL, USA, 2016; pp. 229-259. ISBN 9781420084023.

31. Tavernelli, I.; Vuilleumier, R.; Sprik, M. Ab Initio Molecular Dynamics for Molecules with Variable Numbers of Electrons. Phys. Rev. Lett. 2002, 88, 213002. [CrossRef] [PubMed]

32. Namazian, M.; Norouzi, P. Prediction of one-electron electrode potentials of some quinones in dimethylsulfoxide. J. Electroanal. Chem. 2004, 573, 49-53. [CrossRef]

33. Winget, P.; Cramer, C.J.; Truhlar, D.G. Computation of equilibrium oxidation and reduction potentials for reversible and dissociative electron-transfer reactions in solution. Theor. Chem. Acc. 2004, 112, 217-227. [CrossRef]

34. Blinco, J.P.; Hodgson, J.L.; Morrow, B.J.; Walker, J.R.; Will, G.D.; Coote, M.L.; Bottle, S.E. Experimental and Theoretical Studies of the Redox Potentials of Cyclic Nitroxides. J. Org. Chem. 2008, 73, 6763-6771. [CrossRef] [PubMed]

35. Li, X.-L.; Fu, Y. Theoretical study of reduction potentials of substituted flavins. J. Mol. Struct. 2008, 856, 112-118. [CrossRef]

36. Roy, L.E.; Jakubikova, E.; Guthrie, M.G.; Batista, E.R. Calculation of One-Electron Redox Potentials Revisited. Is It Possible to Calculate Accurate Potentials with Density Functional Methods? J. Phys. Chem. A 2009, 113, 6745-6750. [CrossRef] [PubMed]

37. Ghosh, D.; Roy, A.; Seidel, R.; Winter, B.; Bradforth, S.; Krylov, A.I. First-Principle Protocol for Calculating Ionization Energies and Redox Potentials of Solvated Molecules and Ions: Theory and Application to Aqueous Phenol and Phenolate. J. Phys. Chem. B 2012, 116, 7269-7280. [CrossRef] [PubMed] 
38. Ho, J.; Ertem, M.Z. Calculating Free Energy Changes in Continuum Solvation Models. J. Phys. Chem. B 2016, 120, 1319-1329. [CrossRef] [PubMed]

39. Flores-Leonar, M.M.; Moreno-Esparza, R.; Ugalde-Saldívar, V.M.; Amador-Bedolla, C. Further insights in DFT calculations of redox potential for iron complexes: The ferrocenium/ferrocene system. Comput. Theor. Chem. 2017, 1099, 167-173. [CrossRef]

40. Phillips, K.L.; Sandler, S.I.; Chiu, P.C. A Method to Calculate the One-Electron Reduction Potentials for Nitroaromatic Compounds Based on Gas-Phase Quantum Mechanics. J. Comput. Chem. 2011, 32, 226-239. [CrossRef] [PubMed]

41. Ribeiro, R.F.; Marenich, A.V.; Cramer, C.J.; Truhlar, D.G. Use of Solution-Phase Vibrational Frequencies in Continuum Models for the Free Energy of Solvation. J. Phys. Chem. B 2011, 115, 14556-14562. [CrossRef] [PubMed]

42. Liptak, M.D.; Shields, G.C. Accurate pKa Calculations for Carboxylic Acids Using Complete Basis Set and Gaussian-n Models Combined with CPCM Continuum Solvation Methods. J. Am. Chem. Soc. 2001, 123, 7314-7319. [CrossRef] [PubMed]

43. Toth, A.M.; Liptak, M.D.; Phillips, D.L.; Shields, G.C. Accurate relative pKa calculations for carboxylic acids using complete basis set and Gaussian-n models combined with continuum solvation methods. J. Chem. Phys. 2001, 114, 4595-4606. [CrossRef]

44. Dutton, A.S.; Fukuto, J.M.; Houk, K.N. Theoretical reduction potentials for nitrogen oxides from CBS-QB3 energetics and (C)PCM solvation calculations. Inorg. Chem. 2005, 44, 4024-4028. [CrossRef] [PubMed]

45. Zare, H.R.; Eslami, M.; Namazian, M.; Coote, M.L. Experimental and Theoretical Studies of Redox Reactions of o-Chloranil in Aqueous Solution. J. Phys. Chem. B 2009, 113, 8080-8085. [CrossRef] [PubMed]

46. Ho, J.; Coote, M.L.; Franco-Pérez, M.; Gómez-Baldaras, R. First-Principles Prediction of the pKas of Anti-inflammatory Oxicams. J. Phys. Chem. A 2010, 114, 11992-12003. [CrossRef] [PubMed]

47. Guerard, J.J.; Tentscher, P.R.; Seijo, M.; Samuel Arey, J. Explicit solvent simulations of the aqueous oxidation potential and reorganization energy for neutral molecules: Gas phase, linear solvent response, and non-linear response contributions. Phys. Chem. Chem. Phys. 2015, 17, 14811-14826. [CrossRef] [PubMed]

48. Boesch, S.E.; Grafton, A.K.; Wheeler, R.A. Electron Affinities of Substituted p-Benzoquinones from Hybrid Hartree-Fock/Density-Functional Calculations. J. Phys. Chem. 1996, 100, 10083-10087. [CrossRef]

49. Baik, M.-H.; Friesner, R.A. Computing Redox Potentials in Solution: Density Functional Theory as A Tool for Rational Design of Redox Agents. J. Phys. Chem. A 2002, 106, 7407-7412. [CrossRef]

50. Namazian, M.; Kalantary-fotooh, F.; Noorbala, M.R.; Searles, D.J.; Coote, M.L. Møller-Plesset perturbation theory calculations of the pKa values for a range of carboxylic acids. J. Mol. Struct. 2006, 758, 275-278. [CrossRef]

51. Kelly, C.P.; Cramer, C.J.; Truhlar, D.G. Aqueous solvation free energies of ions and ion-water clusters based on an accurate value for the absolute aqueous solvation free energy of the proton. J. Phys. Chem. B 2006, 110, 16066-16081. [CrossRef] [PubMed]

52. Ho, J.; Klamt, A.; Coote, M.L. Comment on the Correct Use of Continuum Solvent Models. J. Phys. Chem. A 2010, 114, 13442-13444. [CrossRef] [PubMed]

53. Fu, Y.; Liu, L.; Yu, H.-Z.; Wang, Y.-M.; Guo, Q.-X. Quantum-chemical predictions of absolute standard redox potentials of diverse organic molecules and free radicals in acetonitrile. J. Am. Chem. Soc. 2005, 127, 7227-7234. [CrossRef] [PubMed]

54. Reiss, H.; Heller, A. The Absolute Potential of the Standard Hydrogen Electrode: A New Estimate. J. Phys. Chem. 1985, 89, 4207-4213. [CrossRef]

55. Trasatti, S. The Absolute Electrode Potential: An Explanatory Note (Recommendations 1986). Int. Union Pure Appl. Chem. 1986, 58, 955-966. [CrossRef]

56. Truhlar, D.G.; Cramer, C.J.; Lewis, A.; Bumpus, J.A. Molecular Modeling of Environmentally Important Processes: Reduction Potentials. J. Chem. Educ. 2004, 84, 596-604. [CrossRef]

57. Truhlar, D.G.; Cramer, C.J.; Lewis, A.; Bumpus, J.A. Molecular Modeling of Environmentally Important Processes: Reduction Potentials. J. Chem. Educ. 2007, 84, 934, (Corrections: J. Chem. Educ. 2004, 81, 596-603). [CrossRef]

58. Fawcett, W.R. The ionic work function and its role in estimating absolute electrode potentials. Langmuir 2008, 24, 9868-9875. [CrossRef] [PubMed] 
59. Donald, W.A.; Leib, R.D.; O’Brien, J.T.; Bush, M.F.; Williams, E.R. Absolute standard hydrogen electrode potential measured by reduction of aqueous nanodrops in the gas phase. J. Am. Chem. Soc. 2008, 130, 3371-3381. [CrossRef] [PubMed]

60. Bates, R.G.; Macaskill, J.B. Standard Potential of the Silver-Silver Chroride Electrode. Int. Union Pure Appl. Chem. 1978, 50, 1701-1706.

61. Frisch, M.J.; Trucks, G.W.; Schlegel, H.B.; Scuseria, G.E.; Robb, M.A.; Cheeseman, J.R.; Scalmani, G.; Barone, V.; Mennucci, B.; Petersson, G.A.; et al. Gaussian 09 Manual; Revision D.01; Gaussian, Inc.: Wallingford, CT, USA, 2009.

62. Namazian, M.; Norouzi, P.; Ranjbar, R. Prediction of electrode potentials of some quinone derivatives in acetonitrile. J. Mol. Struct. 2003, 625, 235-241. [CrossRef]

63. Hill, J.G. Gaussian Basis Sets for Molecular Applications. Int. J. Quant. Chem. 2013, 113, 21-34. [CrossRef]

64. Cossi, M.; Rega, N.; Scalmani, G.; Barone, V. Energies, structures, and electronic properties of molecules in solution with the C-PCM solvation model. J. Comput. Chem. 2003, 24, 669-681. [CrossRef] [PubMed]

65. Marenich, A.V.; Cramer, C.J.; Truhlar, D.G. Universal solvation model based on solute electron density and on a continuum model of the solvent defined by the bulk dielectric constant and atomic surface tensions. J. Phys. Chem. B 2009, 113, 6378-6396. [CrossRef] [PubMed]

66. Emel'yanova, N.; Sanina, N.; Krivenko, A.; Manzhos, R.; Bozhenko, K.; Aldoshin, S. Comparison of pure and hybrid DFT functionals for geometry optimization and calculation of redox potentials for iron nitrosyl complexes with " $\mu-S C N$ " bridging ligands. Theor. Chem. Acc. 2013, 132, 1316. [CrossRef]

67. Jinnouchi, R.; Anderson, A.B. Aqueous and Surface Redox Potentials from Self-Consistently Determined Gibbs Energies. J. Phys. Chem. C 2008, 112, 8747-8750. [CrossRef]

68. Zhao, Y.; Truhlar, D.G. The M06 suite of density functionals for main group thermochemistry, thermochemical kinetics, noncovalent interactions, excited states, and transition elements: Two new functionals and systematic testing of four M06-class functionals and 12 other function. Theor. Chem. Acc. 2008, 120, 215-241. [CrossRef]

69. Grimme, S.; Antony, J.; Ehrlich, S.; Krieg, H. A consistent and accurate ab initio parametrization of density functional dispersion correction (DFT-D) for the 94 elements H-Pu. J. Chem. Phys. 2010, 132. [CrossRef] [PubMed]

70. Smith, D.G.A.; Burns, L.A.; Patkowski, K.; Sherrill, C.D. Revised Damping Parameters for the D3 Dispersion Correction to Density Functional Theory. J. Phys. Chem. Lett. 2016, 7, 2197-2203. [CrossRef] [PubMed]

71. Guerard, J.J.; Arey, J.S. Critical Evaluation of Implicit Solvent Models for Predicting Aqueous Oxidation Potentials of Neutral Organic Compounds. J. Chem. Theory Comput. 2013, 9, 5046-5058. [CrossRef] [PubMed]

72. Marenich, A.V.; Ho, J.; Coote, M.L.; Cramer, C.J.; Truhlar, D.G. Computational electrochemistry: Prediction of liquid-phase reduction potentials. Phys. Chem. Chem. Phys. 2014, 16, 15068-15106. [CrossRef] [PubMed]

73. Ho, J. Are thermodynamic cycles necessary for continuum solvent calculation of pKas and reduction potentials? Phys. Chem. Chem. Phys. 2015, 17, 2859-2868. [CrossRef] [PubMed]

(C) 2018 by the authors. Licensee MDPI, Basel, Switzerland. This article is an open access article distributed under the terms and conditions of the Creative Commons Attribution (CC BY) license (http:/ / creativecommons.org/licenses/by/4.0/). 